Technical Progress Report

for the

First Quarter

DOE/PC/89789--T5

DE92 015799

(September 1, 1989 - November 30, 1989)

\title{
Control of Pyrite Surface Chemistry in Physical Coal Cleaning
}

\author{
by
}

G.H. Luttrell, R.H. Yoon, J. Zachwieja, and M. Lagno

Department of Mining and Minerals Engineering Virginia Polytechnic Institute and State University

Blacksburg, Virginia 2406?

Grant Number:

$D E-F G 22-89 P C 89789$

Program Officer:

Sayeed Akhtar

U.S. Department of Energy

P.0. Box 10940

Pittsburgh, Pennsylvania 15236

U.S. DOE patent clearance is not required prior to publication of this document. 
ABSTRACT

To better" understand the flotation behavior of coal pyrite, studies have been initiated to characterize the flotability of coal pyrite and mineral pyrite. The hydrophobicity of coal and mineral pyrite was examined over a range of $\mathrm{pH}$ and oxidation times. The results indicate that surface oxidation plays an important role in coal and mineral pyrite hydrophobicity. The hydrophobicity of mineral pyrite decreases with increasing oxidation time (20 min. to $5 \mathrm{hr}$.$) and increasing \mathrm{pH}(\mathrm{pH} 4.6$ to 9.2), with maximum depression occurring at pH 9.2. However, coal pyrite exhibited low flotability, even at the lowest oxidation time, over the entire $\mathrm{pH}$ range. X-ray photoelectron spectroscopy (XPS) results suggest the growth of an oxidized iron layer as being responsible for the deterioration in flotability, while a sulfurcontaining species present on the sample surfaces may promote flotability. Preliminary studies of the effect of frother indicate an enhancement in the flotability of both coal and mineral pyrite over the entire $\mathrm{pH}$ range.

\section{DISCLAIMER}

This report was prepared as an account of work sponsored by an agency of the United States Government. Neitter the United States Government nor any agency thereof, nor any of their employees, makes any warranty, express or implied, or assumes any legal liability or responsibility for the accuracy, completeness, or usefulness of any information, apparatus, product, or bility for the accuracy, completeness, or usefulness of any information, appanalus, product, or ence herein to any specific commercial product, process, or service by trade name, trademark, manufacturer, or otherwise does not necessarily constitute or imply its endorsement, recommendation, or favoring by the United States Government or any agency thereof. The views and opinions of authors expressed herein do not necessarily state or reflect those of the United States Government or any agency thereof. 


\section{INTRODUCTION}

The primary objective of this research is to obtain fundamental knowledge concerning the surface properties of coal pyrite as they relate to advanced physical coal cleaning (APCC) processes. This goal may be met by: investigating the mechanisms responsible for the inefficient rejection of coal pyrite and (2) developing schemes for improving the rejection of coal pyrite based on information gathered from part (1). The selectivity achieved in APCC processes relies greatly on the interfacial properties of the coal and associated mineral matter, in addition to the environment in which these processes operate.

One area of physical coal cleaning where any improvement in the rejection of coal pyrite would be beneficial is flotation processing. In particular, the microbubble column flotation (MCF) process developed at Virginia Tech is one process in which control of the surface properties of coal pyrite may improve selectivity. A better understanding of the flotation behavior of coal pyrite is needed and will be obtained through investigation of the surface chemical properties. The flotability of coal and minerals can be investigated using microflotation tests arid induction time measurements. These two techniques are capable of deterinining the hydrophobicity of the investigated system. In order to determine the species responsible for the observed hydrophobicity and to provide clues as to the mechanism(s) by which the hydrophobicity is produced, surface sensitive techniques such as $X$-ray photoelectron spectroscopy (XPS) and fourier transform infrared spectroscopy (FTIR) can be coupled with the hydrophobicity measurements.

The objective of the research conducted during the first reporting period was to characterize the flotability of coal pyrite and mineral pyrite (chosen as a model substrate). Studies of mineral pyrite hydrophobicity by other researchers indicate that the flotation behavior of pyrite may be affected by the surface oxidation of the particles. Other possible reasons for the 
apparent hydrophobiuty of coal pyrite are interactiuns with reagents in the flotation pulp and/or the presence of hydrocarbons at the surface. In this study, the hydrophobicity of coal and mineral pyrite was examined over a range of $\mathrm{pH}$ and oxidation times. XPS studies were conducted on the samples in conjunction with the hydrophobicity measurements to determine the nature of the species responsible for the observed changes in hydrophobicity. Studies of the effect of hydrocarbons (i.e. frothers and collectors) were initiated and preliminary results are reported.

\section{EXPERIMENTAL}

\section{Sample Preparation}

A mineral pyrite sample from Huanzala, Peru was obtained from Ward's Natural Science Establishment. The sample was stored in bulk crystalline form. Flotation, induction time, and XPS samples were prepared by dry grinding in an agate mortar and pestle and screening to obtain the $100 \times 150$ mesh fraction. To minimize oxidation effects, samples were ground just prior to every test. The $100 \times 150$ mesh fraction was wet screened and rinsed over a vacuum filter to remove any finer particles adhering to the surface. Initial flotation and induction time tests were performed without wet screening and it was found that the flotability was severely hindered by these fine slime particles.

Coal pyrite samples from the Pocahontas No. 3 seam were from a bulk sample of Diester table refuse. The sample was frozen in slurry form when received from the plant. For each test series, approximately 300 grams of frozen materia? was removed from the bulk sample, thawed and dried under a vacuum and then returned to the freezer. As needed, the dried samples were screened to obtain a $10 \times 28$ mesh fraction. From this sample, pyrite particles were hand-picked and ground and wet screened to $100 \times 150$ mesh for use in the test series. 
Induction Time and croflotation Measurements

Induction time was measured using an electronic induction timer developed at Virginia Tech. The instrument is capable of measuring induction times ranging from 1 to 4000 milliseconds. Flotation tests were performed in a microflotation cell in which bubbles were produced by introducing nitrogen gas through a glass frit in the bottom of the cell. For each set of induction time and flotation measurements, one-half gram of pyrite was used for each technique. For those test series that included induction time, microflotation and XPS tests, approximately 3 grams of $100 \times 150$ mesh coal or mineral pyrite particles was selected as the test sample. The sample was split into three 0.8 gram flotation/XPS samples and one 0.5 gram induction time sample. Before each test, approximately 0.3 grams of sample was removed for XPS analys is and the remaining 0.5 gram sample was floated in the microflotation cell. The 0.5 gram sample for the corresponding induction time measurements was oxidized in the induction time cell for the duration of the test period.

Buffered solutions (pH 4.6 acetic acid/sodium acetate buffer; $\mathrm{pH} 6.8$ sodium/potassium phosphate buffer; $\mathrm{pH} 9.2$ sodium borate buffer) were used in all flotation and induction time tests. Tests were also conducted using $\mathrm{HCL}$ and $\mathrm{NaOH}$ for $\mathrm{pH}$ control to ensure that the buffers were not interfering with the test results. No differences were observed.

\section{Spectroscopic Analysis}

The XPS samples were obtained by drying the flotation samples on a vacuum frit. The samples were first rinsed several times in 18 megaohm deionized water to insure that all buffer solution was removed from the surface. Samples were mounted and inserted into the spectrometer vacuum as quickly as possible to minimize carbon contamination. The sulfur $2 p$ lines were fitted using a curve fitting program with a Gaussian-peak shape. All binding energies were charge corrected to the carbon $1 \mathrm{~s}$ line which has a value of $284.9 \mathrm{eV}$. 


\section{RESULTS AND DISCUSSION}

Induction Time and Microflotation Measurements

General

Induction time measurements and flotation recoveries were found to correlate well in tests with mineral pyrite. As should be expected, induction time increases as flotation recovery decreases. In cases where flotation recovery drops to zero, little or no attachment is observed even at the longest ( $4000 \mathrm{msec}$ ) induction time setting. It was found that bubble size, distance of travel of the bubble, and the force with which the bubble contacts the particle bed are critical factors in induction time measurements. These factors must be kept constant in order to avoid falsely low induction times caused by impacting the particle bed with too much force.

The correlation between induction time and microflotation recovery is particularly useful in studies where flotability is to be monitored over time. Unlike flotation tests in which the sample is good for only one test because it is altered (i.e. exposed to the flotation gas and dried to obtain recovery data), induction time measurements offer continuous in situ analysis. Thus, kinetic data can be obtained from the same sample.

Effect of $\mathrm{pH}$ and oxidation

The effect of $\mathrm{pH}$ and oxidation time on the flotability and induction time of mineral and coal pyrite are shown in Figures 1 and 2, respectively. For each test series, the samples were conditioned in buffer solutions for the specified amount of time $(20 \mathrm{~min} ., 1.5 \mathrm{hr}$, and $5 \mathrm{hr}$.$) prior to$ microflotation. Induction times were measured at 30 -minute intervals over the entire five-hour period. The induction time and microflotation recovery results correlate well for both the mineral and coal pyrite tests.

At $\mathrm{pH}$ 4.6, mineral pyrite (Figure 1) exhibits maximum flotability (98\% recovery) with a corresponding minimum induction time (10 $\mathrm{msec})$. The flotability and induction time appear to be insensitive to oxidation as the 


\section{MINERAI PYRITE - PERU \\ FLOTATION TIME $=2 \mathrm{~min}$.}

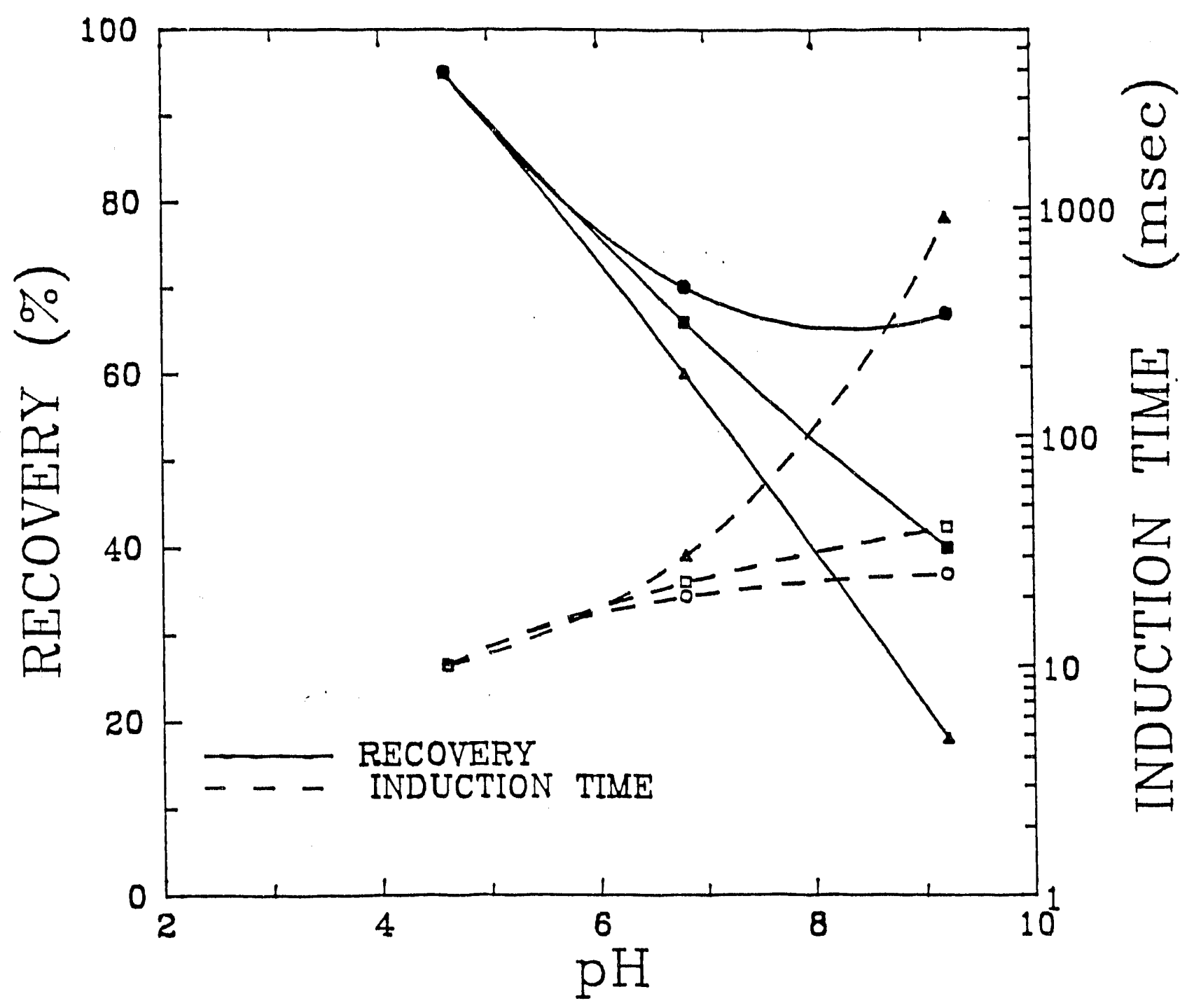

Figure 1. Microflotation recovery and induction time for mineral pyrite in buffered $\mathrm{pH}$ solutions $(\mathrm{pH}=4.6,6.8,9.2)$ over a range of oxidation times $(0,0=20 \mathrm{~min} . ; \Delta, \boldsymbol{\omega}=1.5 \mathrm{hr} . ; \Delta, \Delta=5 \mathrm{hr}$.$) .$ 


\section{COAL PYRITE - POCAHONTAS NO. 3 $10 \times 28$ mesh \\ FLOTATION TIME $=2 \mathrm{~min}$.}

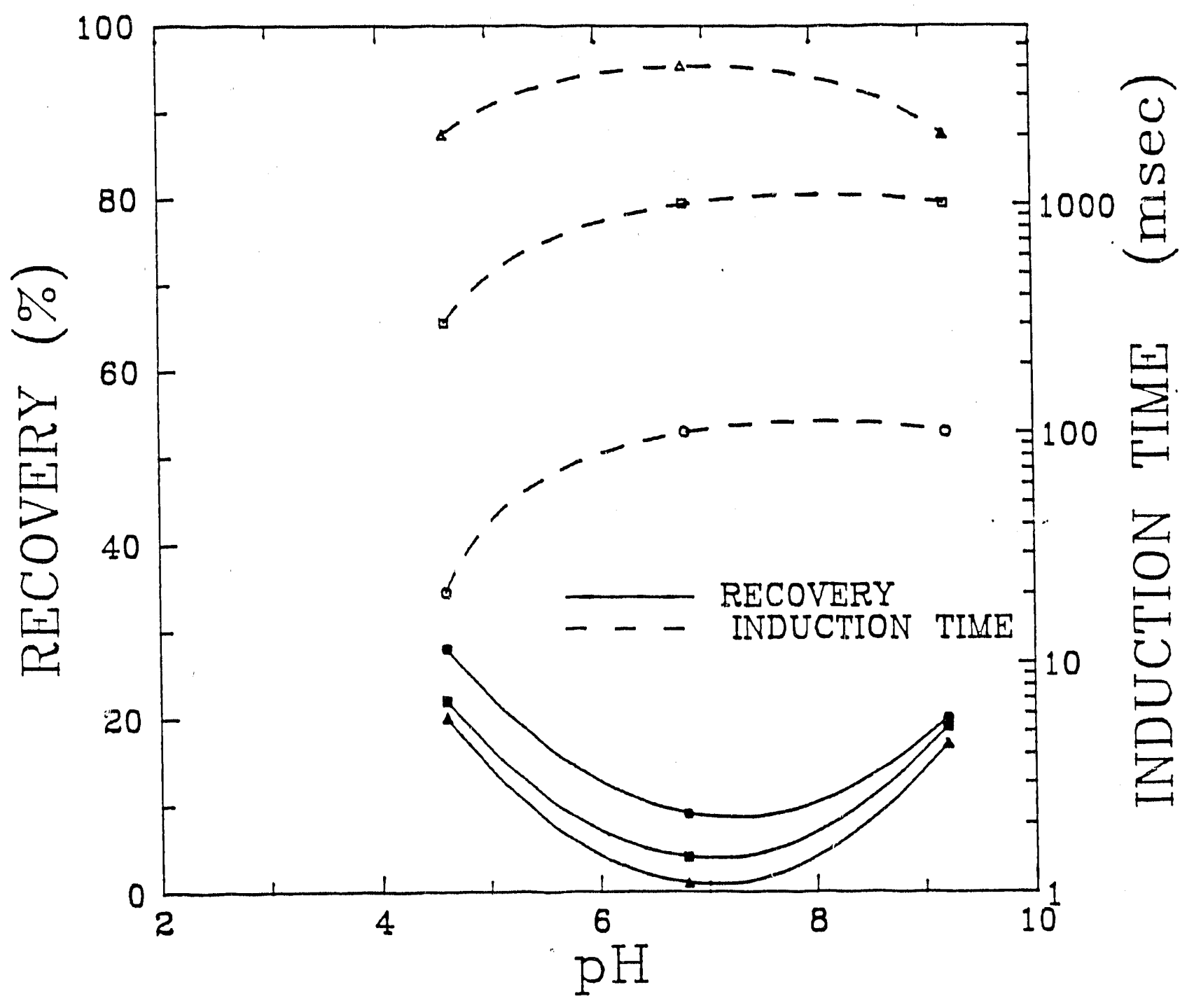

Figure 2. Microflotation recovery and induction time for Pocahontas No. 3 coal pyrite in buffered $\mathrm{pH}$ solutions $(\mathrm{pH}=4.6,6.8,9.2)$ over a range of oxidation times $(0, \bullet=20 \mathrm{~min} . ; a, \omega=1.5 \mathrm{hr} . ;$

$\Delta, \Delta=5 \mathrm{hr}$.). 
oxidation time was increased from $20 \mathrm{~min}$. to $5 \mathrm{hr}$. At a near neutral $\mathrm{pH}$ (pH 6.8), the initial flotability $(68 \%$ recovery) was somewhat lower than that at $\mathrm{pH} 4.6$ and the initial induction time was slightly higher $(20 \mathrm{msec})$. The flotability decreased and the induction time increased as the oxidation time was increased. The most dramatic changes occurred at $\mathrm{pH} \mathrm{9.2.} \mathrm{The} \mathrm{initial}$ flotability and induction time were very close to those observed at $\mathrm{pH} 6.8$; however, as the oxidation time was increased, the flotability decreased to a minimum value (20\% recovery) and the induction time reflected this behavior by increasing to a maximum value $(1000 \mathrm{msec})$ after $5 \mathrm{hr}$. These results show that the microflotation recovery and induction time of mineral pyrite are dependent on $\mathrm{pH}$ and oxidation time.

The results obtained for coal pyrite from the Pocahontas No. 3 seam are seen in Figure 2. Several differences between coal pyrite and mineral pyrite were observed not only for various $\mathrm{pH}$ treatments but also for the oxidation time. The most striking differences are the overall lowering of the initial flotability of the coal pyrite and the sensitivity of the measured induction time, at pH 4.6 and 6.8 , to oxidation time. The maximum flotability occurs at $\mathrm{pH} 4.6$ with a minimum in flotability at $\mathrm{pH} 6.8$. Changes in the flotability with increasing oxidation time are small (approximately 10\%); however, the induction time increased dramatically as the oxidation time was increased for each pH examined. From these measurements alone, it is difficult to define a mechanism(s) responsible for the dependence of mineral pyrite hydrophobicity on $\mathrm{pH}$ and oxidation time. The same is true for the overall decrease in coal pyrite flotabi: ity and the increased sensitivity of its induction time to oxidation. Thus, examination of the mineral and coal pyrite surfaces immediately following microflotation by a surface sensitive technique (e.g., XPS) would be useful in characterizing changes of these surfaces as a result of the various $\mathrm{pH}$ and oxidation treatments. 


\section{XPS Analysis}

The results of XPS measurements performed in conjunction with the microflotation and induction time tests presented in the previous section are shown in Figures 3 and 4 and Tables 1 through 4 . XPS spectra were collected for the oxygen $1 s$, carbon $2 s$, sulfur $2 p$, iron $2 p$, and iron $3 p$ peaks. When additional peaks were observed in the wide scan spectra, those peaks were also collected. Silicon, phosphorous, and calcium peaks were those most commonly observed. For each test, the sulfur $2 p$ peak was deconvoluted using a data analysis program provided with the XPS instrument. Good fits were obtained when multiple peaks were employed, as shown in, Figure 7 . That is, the peak could not be fitted with a single component with position and size corresponding to published sulfur $2 p$ spectra. Rather, multiple peaks of lesser intensity and shifted to a higher binding energy also had to be included to obtain a proper fit. This indicates that the surfaces of the particles contain some altered sulfur species. There is much debate concerning the identity of these sulfur species and at this time the generic label "sulfoxy species" is the only name given to them.

In Tables 1 and 3 , the fourth column (\% Sulfide) represents the portion of the sulfur $2 p$ peak that is in the sulfide position. It was calculated by subtracting the area of the "sulfoxy" peaks from the total peak area. The "sulfoxy" species were observed in both the mineral and coal pyrite samples and occurred over the examined $\mathrm{pH}$ range. The general trend observed for these data indicates that as the flotability increases (Figures 1 and 2), the percentage of "sulfoxy" also increased; however, it is difficult to use these values quantitatively. Also, the percent "sulfoxy" exhibited a slight decrease with increasing oxidation time. This could be due to the loss of sulfur as soluble sulfate.

In Tables 2 and 4 , data which represent the percentage oxide are tabulated and were calculated using the $\mathrm{Fe} 2 \mathrm{p}$ peak. The $\mathrm{Fe} 2 \mathrm{p}$ peak for iron in an 


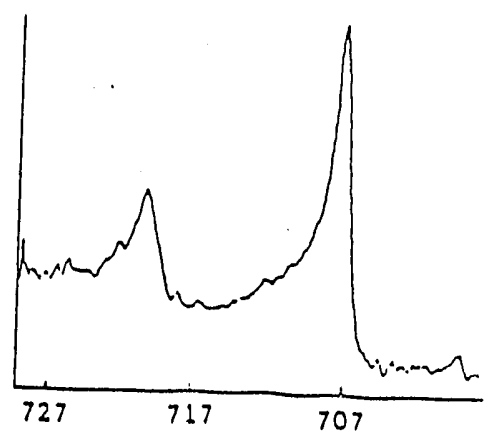

FRESH GRIND

鼠

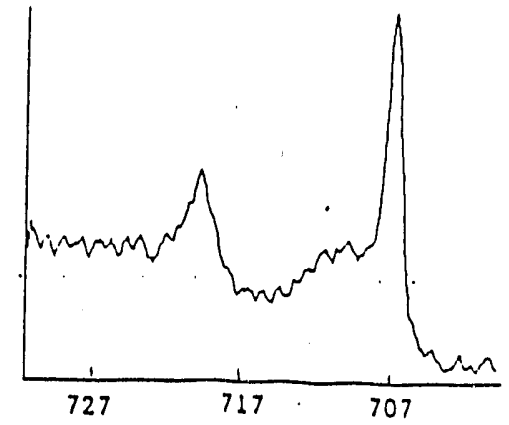

20 MINUTES, $\mathrm{pH}=9.2$

5 HOURS, $\quad \mathrm{pH}=9.2$

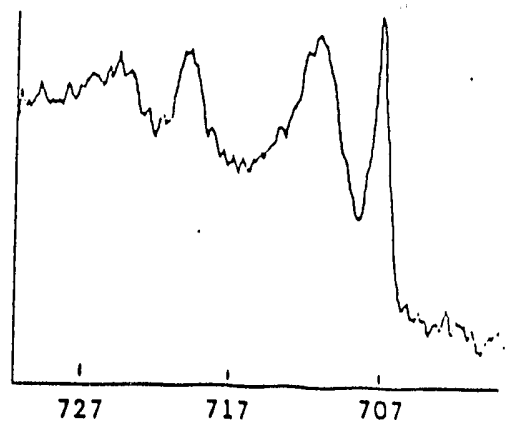

$1 \mathrm{MONTH}, \quad \mathrm{pH}=9.2$

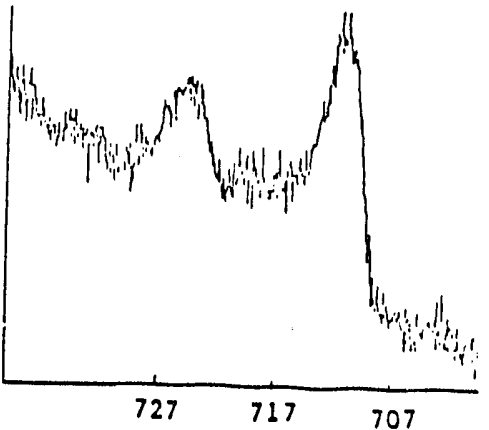

BINDING ENERGY, eV

Figure 3. Iron 2p spectrum for mineral pyrite over a range of oxidation times in $\mathrm{pH} 9.2$ buffer. 

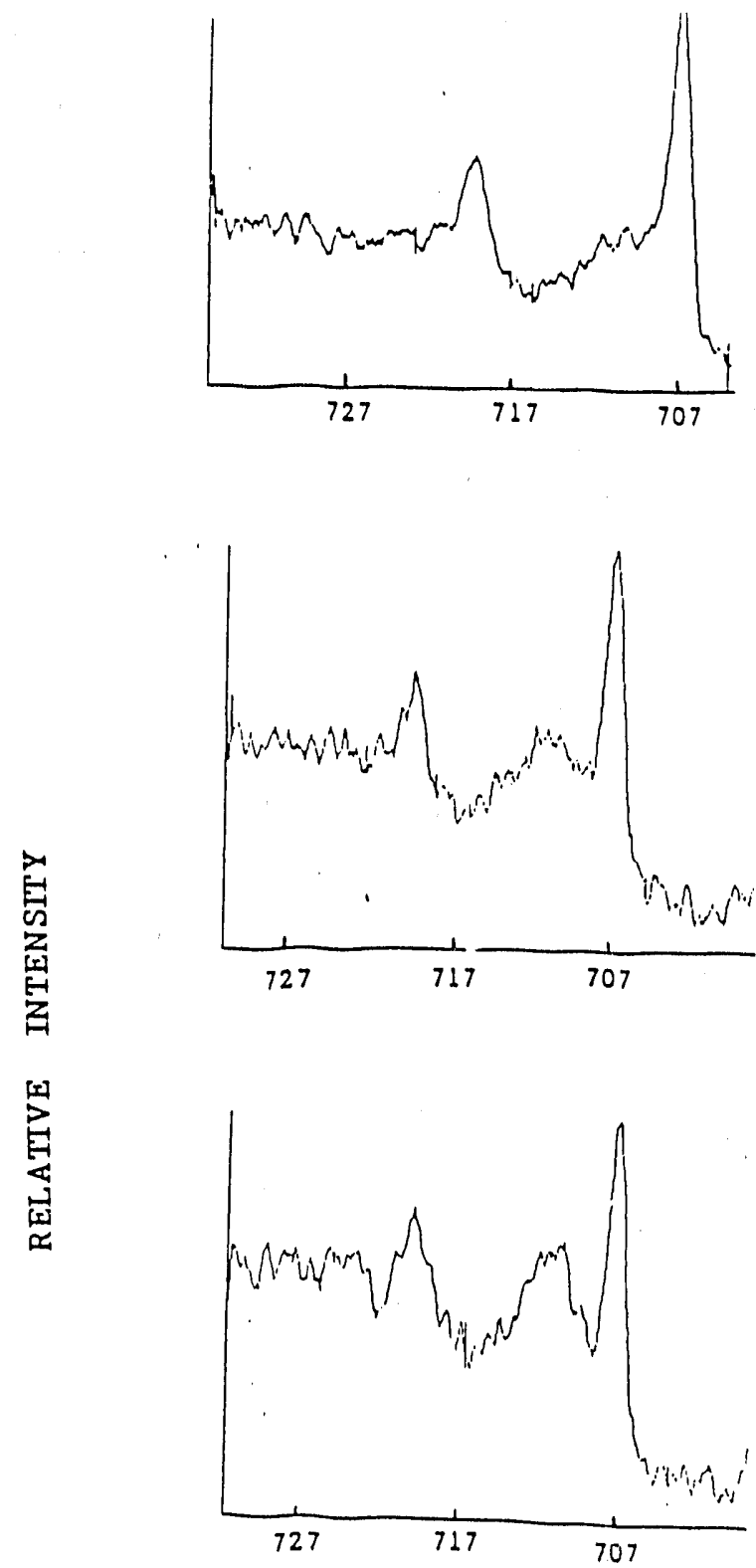

20 MINUTES, $\mathrm{pH}=9.2$
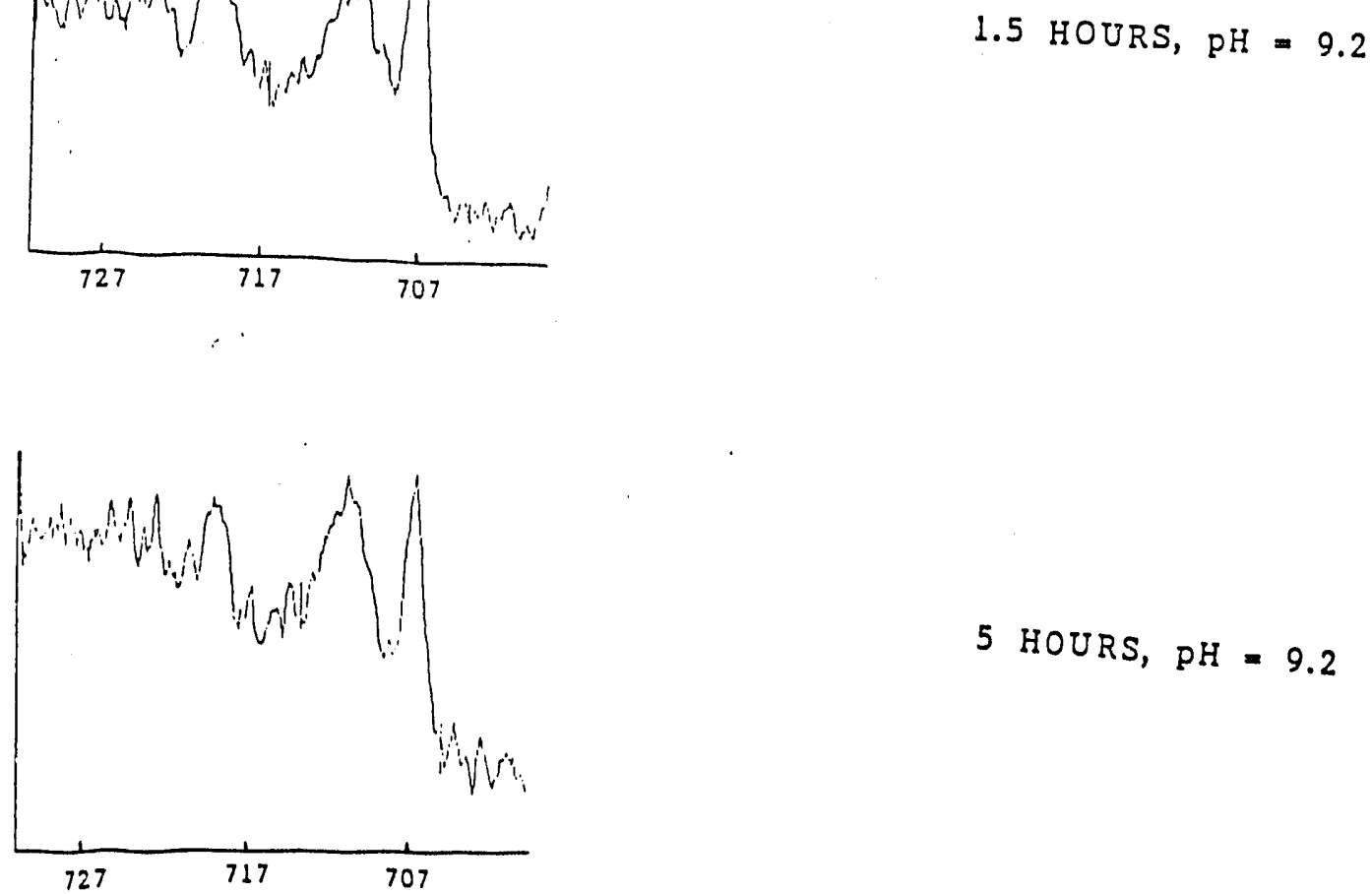

5 HOURS, $\mathrm{pH}=9.2$

BINDING ENERGY, eV

Figure 4. Iron 2p spectrum for Pocahontas No. 3 coal pyrite over a range of oxidation times in $\mathrm{pH} 9.2$ buffer. 
Table 1. XPS peak nnsitions for inineral pyrite as a function of $\mathrm{pH}$ and oxidatiol. ime (time in solution $=20 \mathrm{~min} 1.5 \mathrm{hr} ., 5 \mathrm{hr}$.).

\begin{tabular}{|c|c|c|c|}
\hline sampie & $\begin{array}{c}\text { S 2P3/2 (sulfide) } \\
(\mathrm{ev})\end{array}$ & $\begin{array}{c}52 P 3 / 2(s u 1 \text { foxy) } \\
(e v)\end{array}$ & $\%$ sulfide \\
\hline Peru 4.6 (20 min.) & 162.2 & 164.0 & 86 \\
\hline Peru 4.6 (1.5 hrs.) & 162.5 & 164.4 & 88 \\
\hline Peru 4.6 (5 hrs.) & 162.5 & 164.6 & 89 \\
\hline Peru 6.8 (20 min.) & 162.5 & 164.1 & 86 \\
\hline Peru 6.8 (1.5 hrs.) & 162.5 & 164.1 & 86 \\
\hline Peru 6.8 ( 5 hrs.) & 162.6 & 164.3 & 85 \\
\hline Peru 9.2 (20 min.) & 162.3 & 163.9 & 91 \\
\hline Peru 9.2 (5 hrs.) & 162.3 & 163.9 & 91 \\
\hline Peru 9.2 (1 month) & $N / D$ & $N / D$ & $N / D$ \\
\hline Peru Dry Grind & 162.1 & 163.4 & 80 \\
\hline
\end{tabular}

Table 2. XPS relative intensities for mineril pyrite as a function of $\mathrm{pH}$ and oxidation time ( $t$ ime in solution $=20 \mathrm{~min} ., 1.5 \mathrm{hr} ., 5 \mathrm{hr}$.).

\begin{tabular}{|c|c|c|c|c|}
\hline sample & ratio $\mathrm{Fe} 3 \mathrm{p} / \mathrm{S} 2 \mathrm{p}$ & $\begin{array}{c}\text { Fe } 2 p 3 / 2 \\
\text { (ev) } \\
\end{array}$ & \% oxide & ratio $01 \mathrm{~s} / \mathrm{S} 2 \mathrm{p}$ \\
\hline Peru 4.6 (20 min.) & 0.33 & 707.5 & 7 & 0.34 \\
\hline Peru 4.6 (1.5 hrs.) & 0.33 & 707.7 & 9 & 0.23 \\
\hline Peru 4.6 (5 hrs.) & 0.31 & 707.7 & 6 & 0.23 \\
\hline Peru $6.8(20 \mathrm{~min})$. & 0.37 & 707.7 & 18 & 0.73 \\
\hline Peru 6.8 ( 1.5 hrs.) & 0.35 & 707.6 & 25 & 0.87 \\
\hline Peru 6.8 (5 hrs.) & 0.33 & 707.6 & 29 & 0.95 \\
\hline Peru 9.2 (20 min.) & 0.36 & 707.5 & 17 & 0.48 \\
\hline Peru 9.2 (5 hrs.) & 0.55 & 707.6 & 53 & 1.29 \\
\hline Peru 9.2 (1 month) & 13.2 & - & 100 & 55.1 \\
\hline Peru Dry Grind & 0.36 & 707.5 & 0 & 0.36 \\
\hline Theoretical FeS2 & 0.53 & & & \\
\hline Brion & & 707.4 & & \\
\hline
\end{tabular}


Table 3. XPS peak positions for Pocanontas No. 3 coal pyrite as a runction or oxidatior ime (time in solution $=20 \mathrm{~min} 1.5 \mathrm{hr} ., 5 \mathrm{hr}$.).

\begin{tabular}{|c|c|c|c|}
\hline sample & $\begin{array}{c}\text { S 2P3/2 (sulfide) } \\
(\mathrm{ev})\end{array}$ & $\begin{array}{c}\text { S 2P3/2 (suifoxy) } \\
\frac{(\mathrm{ev})}{}\end{array}$ & $\%$ sulfide \\
\hline Coal 4.6 (20 min.) & 101.9 & 163.5 & 84 \\
\hline Colal $4.6(1.5 \mathrm{hr})$. & 161.9 & 163.6 & 84 \\
\hline Coal 4.6 (5 hr.) & 161.9 & 163.9 & 90 \\
\hline Cidal 6.8 (20 min.) & 162.2 & 163.8 & 90 \\
\hline Coal $6.8(1.5 \mathrm{hr})$. & 162.2 & 164.0 & 89 \\
\hline Coal $6.8(5 \mathrm{hr})$. & 162.3 & 163.9 & 89 \\
\hline (coal $9.2(20 \mathrm{~min})$. & 162.0 & $163 . \ddot{6}$ & 86 \\
\hline Loal $9.2(1.5 \mathrm{hr})$. & 162.2 & 162.9 & 95 \\
\hline Coal $9.2(5 \mathrm{hr})$. & 162.1 & 163.8 & 96 \\
\hline Coal Dry Grind & 162.3 & 164.2 & 87 \\
\hline Coal Air Oxidized & 162.5 & $164.8 / 167.9$ & 82 \\
\hline
\end{tabular}

Table 4. XPS relative intensities for Pocahontas No. 3 coal pyrite as a function of $\mathrm{pH}$ and oxidation time (time in solution $=20 \mathrm{~min}$., $1.5 \mathrm{hr} ., 5 \mathrm{hr}$.$) .$

\begin{tabular}{|c|c|c|c|c|}
\hline sample & ratio $F e 3 p / S 2 p$ & $\begin{array}{c}\text { Fe } 2 p 3 / 2 \\
(e v) \\
\end{array}$ & $\%$ oxide & ratio $01 \mathrm{~s} / \mathrm{S} 2 \mathrm{p}$ \\
\hline Coal 4.6 (20 min.) & 0.36 & 707.1 & 14 & 1.0 \\
\hline Coal $4.6(1.5 \mathrm{hr})$. & 0.36 & 707.2 & 9 & 0.82 \\
\hline Coal $4.6(5 \mathrm{hr})$. & 0.38 & 707.1 & 11 & 0.95 \\
\hline Coal 6.8 (20 min.) & 0.34 & 707.3 & 24 & 1.29 \\
\hline Coal $6.8(1.5 \mathrm{hr})$. & 0.34 & 707.6 & 25 & 1.31 \\
\hline Coal $6.8(5 \mathrm{hr})$. & 0.43 & 707.7 & 39 & 1.68 \\
\hline Coal $9.2(20 \mathrm{~min})$. & 0.37 & 707.3 & 32 & 1.20 \\
\hline Coal $9.2(1.5 \mathrm{hr})$. & 0.47 & 707.3 & 44 & 1.42 \\
\hline Coal $9.2(5 \mathrm{hr})$. & 0.43 & 707.3 & 57 & 1.86 \\
\hline Coal Dry Grind & 0.33 & 707.5 & 14 & 0.83 \\
\hline Coal Air Oxidized & 0.46 & 707.7 & 54 & 1.81 \\
\hline
\end{tabular}


oxidized state exhibits a definite shift in binding energy compared to iron associated with the unoxidized sulfide. This is clearly seen for mineral and coal pyrite at pH 9.2 in Figures 3 and 4 , respectively. The peak which appears at $707.2 \mathrm{eV}$ is the sulfide iron. As the oxidation time increases, the growth of the oxide peak at approximately $711 \mathrm{eV}$ is observed. In the $\mathrm{Fe} 2 \mathrm{p}$ region, it is difficult to positively identify this peak; however, several different oxides/hydroxides of iron appear in this region (i.e., $\mathrm{FeO}(\mathrm{OH})$, $\left.\mathrm{Ce}_{2} \mathrm{O}_{3}, \mathrm{FeO}, \mathrm{Fe}_{3} \mathrm{O}_{4}\right)$. The percent oxide was calculated by subtracting the area for iron sulfide from the total peak. This area was obtained from the spectrum of dry ground mineral pyrite which had a negligible oxide component. The area remaining after subtracting the sulfide was considered the oxide area.

Lual pyrite samples appear to have a larger percentage of oxide as compared to the mineral purite. For both types of pyrite, the percentage of oxide was observed to increase with increases in $\mathrm{pH}$ and oxidation time. The most pronounced increases occurred at $\mathrm{pH} 9.2$ where both coal and mineral pyrite yielded oxide values greater than 50\% within 5 hours. For mineral pyrite, the growth of the oxide layer correlates well with flotation data. At $\mathrm{pH} 4.6$, the flotation recovery and induction time of mineral pyrite do not change appreciably with increasing oxidation time, nor was there growth of the oxide peak. The coal pyrite samples display the growth of the oxide peak; however, all of the samples appear to have been in a more oxidized state initially as compared to the mineral pyrite samples. This initially oxidized condition may be the reason why coal pyrite displays a lower initial flotability as compared with mineral pyrite.

Another interesting trend can be seen in the $01 \mathrm{~s} / \mathrm{S} 2 \mathrm{p}$ ratio shown in Tables 2 and 4 . At $\mathrm{pH} 6.8$ and 9.2, the ratio increases with oxidation time for both mineral and coal pyrite, indicating that more oxygen is present at 
the surface. This oxygen is most likely associated with the growing iron oxide layer. It should also be noted that the $01 \mathrm{~s} / \mathrm{S2p}$ ratio is higher for all of the coal pyrite samples as compared to the mineral pyrite samples, again indicating that these samples were initially in an oxidized state. At pH 4.6, the $01 \mathrm{~s} / \mathrm{S} 2 \mathrm{p}$ ratio is reversed. The ratio decreases with oxidation time which indicates either a decrease in the oxygen at the surface or an increase in the sulfur. The trend in the $015 / S 2 p$ ratio correlates well with flotation behavior. When the $01 \mathrm{~s} / \mathrm{S} 2 \mathrm{p}$ ratio is low, good flotability is observed. Mineral pyrite at $\mathrm{pH} 4.6$ has an $01 \mathrm{~s} / \mathrm{S} 2 \mathrm{p}$ ratio of 0.32 and flotavility of greater than $90 \%$. For all of the coal pyrite samples, the $01 \mathrm{~s} / \mathrm{S} 2 \mathrm{p}$ ratio is greater than 1, and none of these samples exhibit good flotability.

Trends in the Fe3p/S2p ratio, shown in Tables 2 and 4 , al so correlate well with flotation and induction time results. The theoretical ratio calculated by taking into account sensitivity factors for these two elements is 0.53 . Values obtained in this study were lower, even for samples that were freshly ground and quickly put into the spectrometer. This indicates that there is immediate alteration in the surface layer and the decrease in the ratio suggests a sulfur enrichment. The ratio is again lowest for the mineral pyrite sampie at pH 4.6 where the best flotability is observed. For mineral pyrite at $\mathrm{pH} 4.6$ and 6.8 , the ratio deceases with oxidation time. This indicates that sulfur is appearing at the surface at the expense of the iron. At $\mathrm{pH}$ 9.2, however, the ratio increases, indicating an increase in iron at the surface. For extended oxidation (1 month) at $\mathrm{pH} \mathrm{9.2,} \mathrm{the} \mathrm{sulfur} \mathrm{peak} \mathrm{is}$ extremely attenuated, indicating that a complete iron oxide overlayer has formed. The Fe3p/S2p ratio for the coal pyrite samples follows the same trends for each $\mathrm{pH}$ examined. The initial ratio is somewhat lower than the theoretical value of 0.53 , then increases with increasing oxidation time. These results are again evidence for the growth of an iron oxide overlayer and they correlate well with the lower flotability observed for the coal 
pyrite samples.

\section{Effect of Frother}

Upon characterizing the role of surface oxidation in the flotability of coal and mineral pyrite, the next step is to examine the interactions between the pyrite and the typical coal flotation reagents, such as frothers and collectors. Preliminary microflotation and induction time results have been obtained for both coal and mineral pyrite in the presence of the frother methylisobutylcarbinol (MIBC).

The results of microflotation and induction time measurements of freshly ground mineral and coal pyrite in the absence and presence of MIBC as a function of $\mathrm{pH}$ are shown in Figures 5 and 6 , respectively. For both coal and mineral pyrite the microflotation recovery and the corresponding induction time were enhanced by the presence of $10^{-4} \mathrm{M} M I B C$ over the examined range of $\mathrm{pH}$. The enhancement of the flotation recovery may be due to surface tension effects in which smaller, more numerous bubbles were produced in the microflotation cell, thus improving the probability of bubble-particle collision. However, the induction time data do not support this conclusion. Since flotation hydrodynamics are considered insignificant ir. induction time measurements, the lowering of the induction time in the presence of MIBC suggests that there is an interaction between the frother and the pyrite surface. This interaction may occur either by way of the air bubble or by physical adsorption on the pyrite itself. Further studies will prove beneficial in resolving the mechanism of this phenomenon. 


$$
\begin{aligned}
& \text { MINERAL PYRITE }- \text { PERU } \\
& \text { MIBC }\left(1 \text { X } 1.0^{-4} \text { M }\right) \\
& \text { FLOTATION TIME }=2 \text { min. }
\end{aligned}
$$

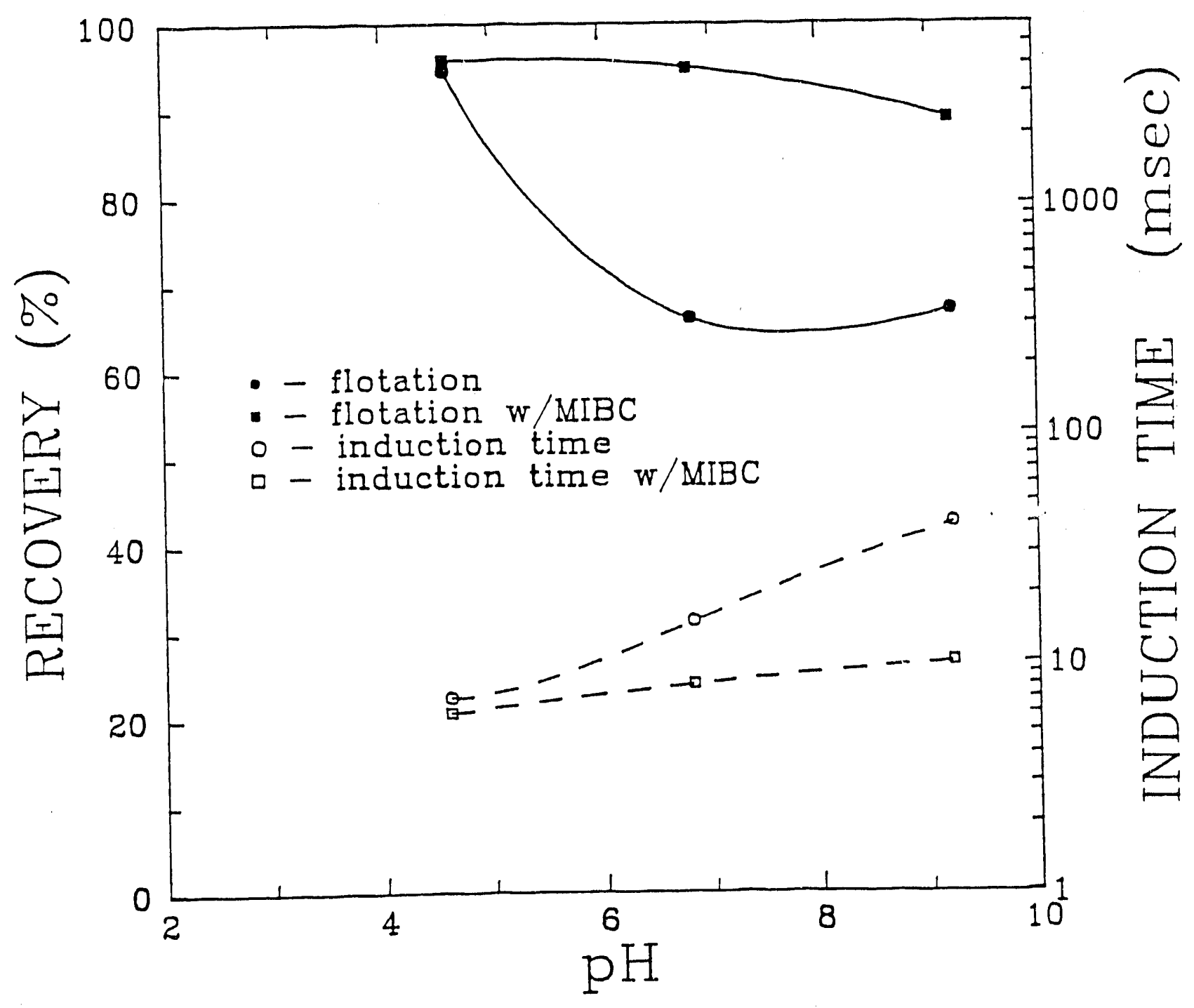

Figure 5. Microflotation recovery and induction time for mineral pyrite in buffered pH solutions. 


\section{COAL PYRITE - POCAHONTAS NO. 3 MIBC \\ FLOTATION TIME $=2 \mathrm{~min}$.}

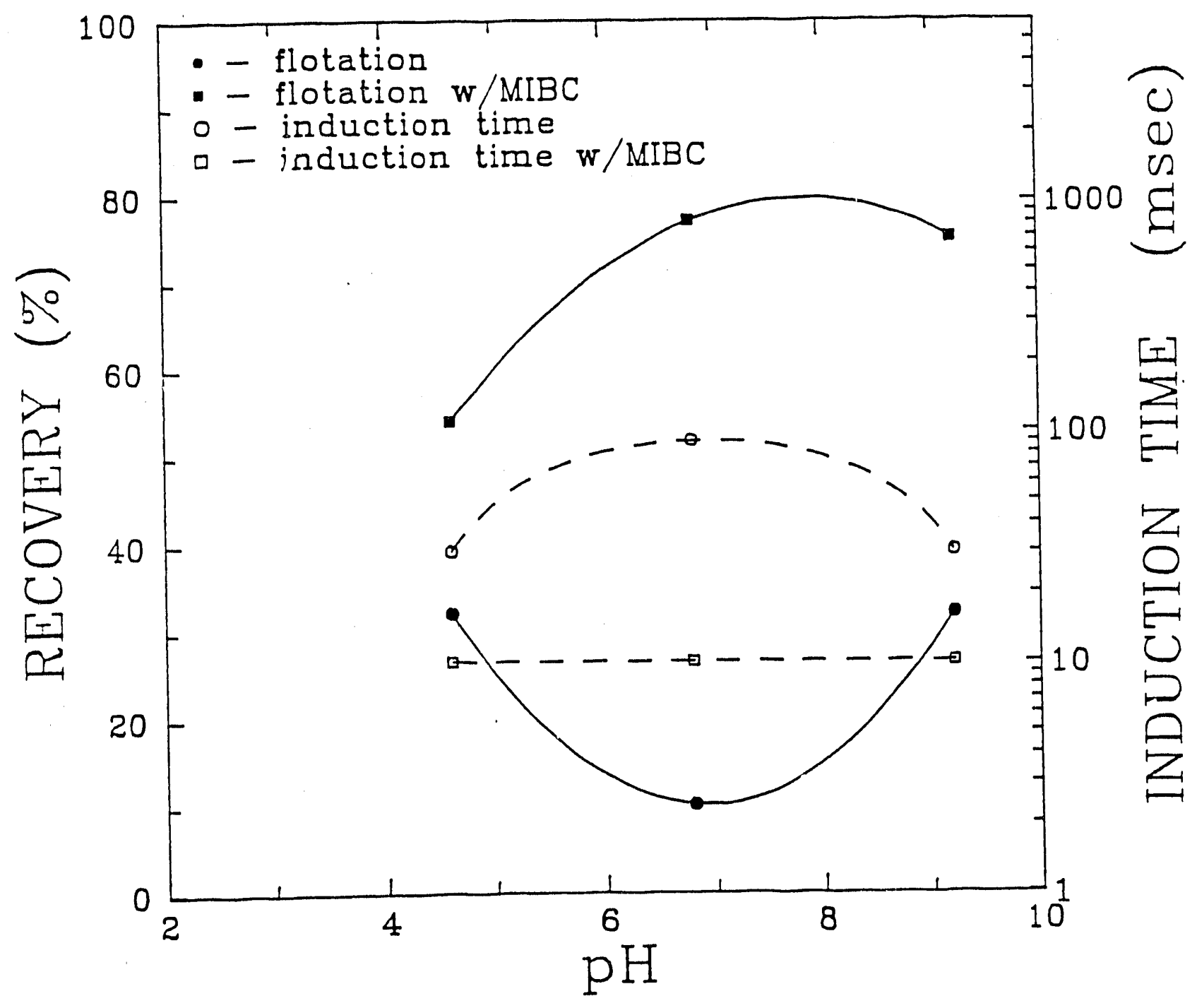

Figure 6. Microflotation recovery and induction time for Pocahontas No. 3 coal pyrite in buffered $\mathrm{pH}$ solutions. 


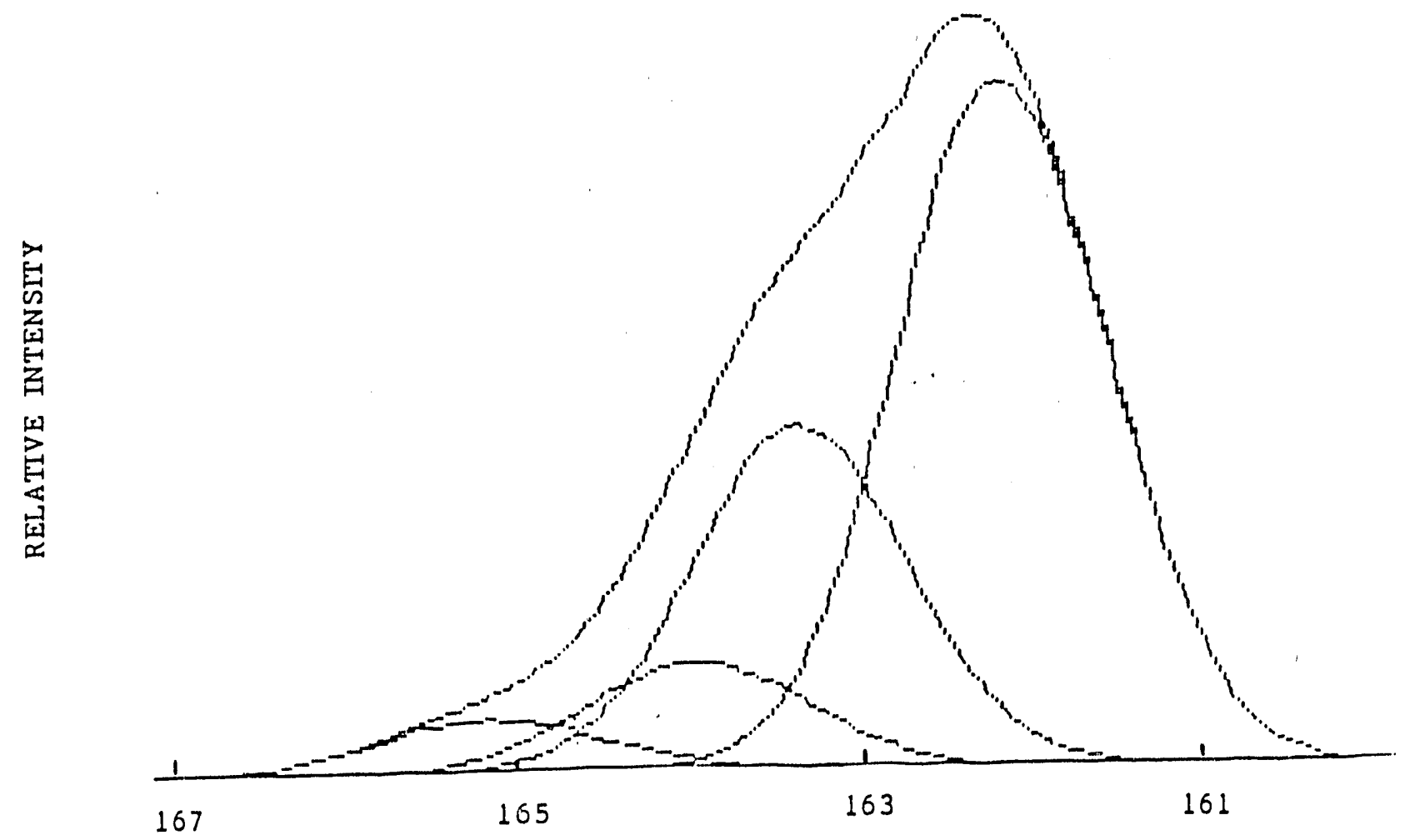

BINDING ENERGY, eV

Figure 7. Deconvoluted sulfur $2 p$ peak for mineral pyrite after oxidation at $\mathrm{pH} 4.6$ for 20 minutes. 


\section{CONCLUSIONS AND FUTURE WORn}

The results presented in this report indicate that induction time, microf'otation, and XPS analysis can be combined and used successfully in the characterization of the hydrophobicity of coal and mineral pyrite. Surface oxidation plays an important role in the hydrophobicity of coal and mineral pyrite and may be used as a control variable in improving the selectivity of coal and pyrite separations. From preliminary tests, the effect of frocher on the hydrophobicity of coal and mineral pyrite appears to be substantial and further studies will determine the impact of hydrocarbons on the selectivity of coal pyrite rejection.

Future work plans aimed at understanding the mechanisms responsible for the inefficiert rejection of coal pyrite include the following studies: (1) the effect of sample source on hydrophobicity, (2) the effect of traditional flotation surfactants on hydrophobicity, (3) the effect of particle size on hydrophobicity, and (4) fundamental oxidation kinetics. 


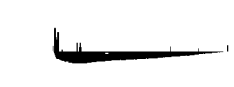

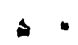
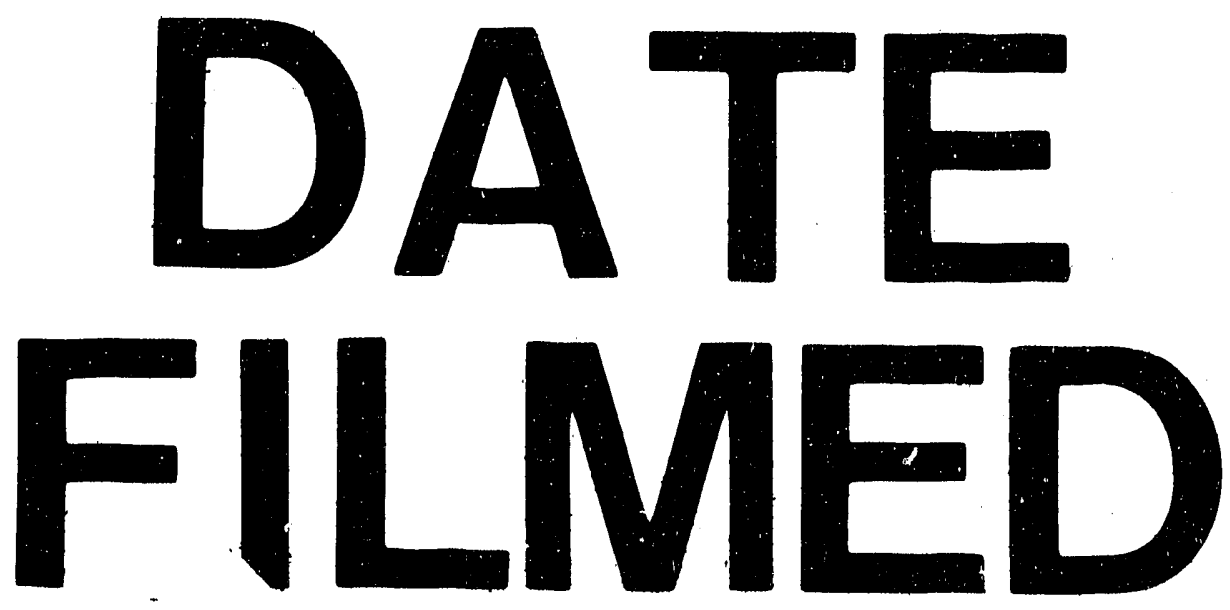

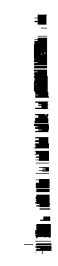

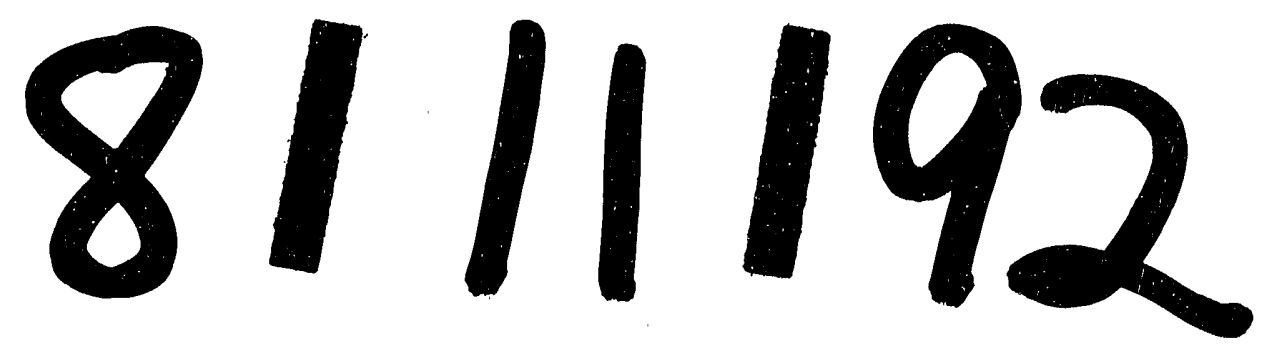


